\title{
The Social Anthropology of Rage and Its Psychotherapeutic Challenge
}

\author{
Theodor Itten \\ Independent Researcher, St. Gallen, Switzerland
}

Email address:

info@ittentheodor.ch

To cite this article:

Theodor Itten. The Social Anthropology of Rage and Its Psychotherapeutic Challenge. International Journal of Science, Technology and Society. Vol. 8, No. 3, 2020, pp. 56-62. doi: 10.11648/j.ijsts.20200803.15

Received: March 2, 2020; Accepted: April 8, 2020; Published: June 17, 2020

\begin{abstract}
Rage - a sudden outburst of explosive and often destructive anger - is part of the human condition. Yet it is one that often hits the headlines in the context of celebrity outburst, domestic violence and road rage. Whether this violent anger is directed at complete strangers or people within our social spheres, it has developed its own terminology - 'losing one's cool, air rage, road rage, trolley rage are all increasingly accepted as a part of the pressures of modern day. This essay offers case studies which supply new socio-psychological and therapeutic insights, based on social-anthropological data. The author goes on to explore the triggers and characteristics associated with rage, from the perspective of both perpetrator and victim. He argues that there are evolutionary factors behind the physiological manifestations of rage - conflicts between our animal instincts and our need to function as a human, in a group. Using the analogy of a volcano to capture the intense energy and unpredictability of episodes of sudden rage, he puts forward several theories for the increasing prevalence of rage in modern society. His social phenomenological research suggests that the incidence of rage is significantly higher in densely populated, industrialized and computerized societies. Drawing on his own in-depth study, carried out in Switzerland, he estimates that around of a quarter of the population are prone to rage attacks - a startlingly high proportion. Itten argues that the therapeutic practitioner has a clear role to play in helping rage sufferers to devise positive strategies to manage their explosive emotions, developing routes out of rage. An open and frank appraisal of the ugly and destructive nature of sudden rage is the starting point, working with sufferers to build a deeper sense of self-esteem and self-confidence, so that they are de-sensitized and learn strategies to defuse anger and cope with situations which previously might have resulted in another explosion.
\end{abstract}

Keywords: Sudden Rage, Social Anthropology, Psychotherapy, Social Psychology

\section{Introduction}

Young people knocking down pensioners, train passengers attacking conductors, parents tormenting their children: uncontrolled outbursts of violence are the order of the day. Sudden rages don't just exist in the margins of society: they're a plague on it. Sudden rages ${ }^{i}$ are damaging. The destructive power of these severe emotional outbursts is well-known, but to a large extent placed under a social taboo. I commissioned a survey of nearly 600 people on their personal experiences of sudden rages. The results surprised me: $20 \%$ had been the victims of raging parents as a child; $24 \%$ per cent admitted to being ragers themselves. We stand helpless before the open secret of a veritable plague to society. One of the main reasons for the recurrence of sudden rages is that civilised engagement with our own animal emotions and human feelings are often not allowed.

\section{The Issue}

Sudden rages, with their glaring eyes, near screaming voice, bristling of hair - ${ }^{\mathrm{ii}}$ can be passed down the generations. Maybe this issue of sudden rage has parallels to the debate on "Moral Borders of Self and Other: Migration, Reconciliation, and Human Wellbeing". iii Angela Hobart and David Napier lay out the matter, that "as psychological distress becomes medicalized, so too are the social conditions (e.g., the destabilizations of warfare, natural disaster, economic migration) that underlie it. Such conditions generate unique moral imperatives that are codified over time as illness categories, social suffering, collective trauma, etc. Some of the recent darkest moments in our dangerous European world 
was the Serbian war against Bosnia Herzegovina. The siege of Sarajevo, from 2 May 1992 till 6 January 1996, was a campaign of unrelenting violence by a professional army against inhabitants of a European city, “... to reduce them to a state of medieval deprivation in which they were in constant fear of death". iv If we remember that 1'500 children have been killed and 15'000 children wounded, there can be no doubt about the destruction implanted in the human psyche of these now grownups of 24 to 35 years old. They, mostly Bosniak (85\%) are struggling to face truth and denial of what war mongers the like of Karazic, Mladic, Milocevic and their western political naïve collaborators intended annihilating the Muslim population of Sarajevo and Bosnia Herzegovina.

\section{Rage Kills}

Ron Roberts, Edina Becirevic and Stephen Paul [1] put this truth on the table, how systematic genocidal pattern of violence was brought to finale in the genocide of Srebrenica in 11 July, 1995. 7'109 men and boys were murdered. Their names are all listed, with dates of birth, in the memorial publication by Tarik Samarah, [2]. Was it then farewell to Bosnia, as Gilles Peress [3]called it with his silent screaming pictures of the war? There is no reconciliation possible without remembrance, feeling the hate and rage in the scars of the soul and body. Perpetrators have to face up to their wrongs and evil deeds done, so that the sufferers, the prey, can accept their acknowledgements and responsibility for this immense suffering caused. The personal is political and a melding of interpersonal processes with institutional action, thus the conclusion of Roberts et al [1] calls for successful fulfilment of the healing recovery processes which depends on coordinated political actions in domestic and international spheres. ${ }^{\mathrm{V}}$ What is going on? As human animal we still are in survival need of warmth, food, drink, shelter, boundary protection and move-ability in the ordered wilderness, which our species has cultivated over thousands of years, once settlement was taken as a choice of survival. From then on, social and garden worlds have become cultured, always on a limited scale, according to our social and aesthetic ideals. "There was nothing democratic about sanctuaries of the ancient world", writes Emily Gowers [4]in her review on $A$ World of Gardens by John Dixon Hunt who makes us aware again, that in the ordered wildernesses, places for meditation and bridges to the numinous of sacredness, admission to such refuges, was monitored by and for the elite (p. 5) Our domestic social living has often been interrupted by youths getting into days of rage, often expressing violently what is enraging them about the economic and political tightness they happen find themselves in.

\section{Social Unrest}

What happened in Tottenham, London in summer 2011, was, according to some participants, nearly a spiritual outburst nay, eruption of rage. The trigger was a social and economic bad time, hot weather, some unjust public event and out comes this deep seated emotion of holy rage in folks who feel trapped in daily living and lacking perspectives. There is no horizon to howl one self too. There is injustice, insecurity, a different hunger, a lack to make a difference that makes a difference only to others, a darkness permeating their tapestry of experience. The night of destruction in Tottenham spread over to many a city in the midlands leaving thousands of shops and streets in ruins. Borger [5] reports from London that, while Olympia is taking place, the wounds have not healed, growing even worse through government economic cuts to youth clubs and sporting associations. Did those for whom this bell tolls listen? No, they just went ahead with more repression, the same old strategy or game since Roman times if not before. Super capitalism rules, ok?

Robert Reich in his analysis of Supercapitalism: The Transformation of Business, Democracy, and Everyday Life has shown how vital it is for us to cultivate our ability to think clearly on these issues of exploitation. In his most recent work, Beyond Outrage [6], Reich presents a shameless analysis of the riggedness of democracy involving a clever covered conspiracy, promising us a perpetual raise of happiness by consuming more and more, while in reality we are seriously damaging our peace of mind, making us grim and, yes, socially angry even prone to sudden rage attacks. Elizabeth Day [7] looks at the effect which mass produced happiness has on us, 'while marginalising sadness, undermining our yearning impulse that has produced some of our greatest creative minds.'(p. 23) But simple questions remains: Who profits? Who benefits? Who is betrayed? When street life gets out of hand, protests land on trial. Our colleague Jerome Kagan [8] goes on with verve "... elected representatives in Washington gave billions of dollars to banks and automobile companies to rescue them from the consequences of the extremely risky decisions their corporate leaders made but little to save millions of poor families who lost their homes because they too assumed the risk of buying a house they could not afford. (Knowing they have been talked into taking this risk by mortgage bank reps, being pulled over the table, usually having thus lost all their previous hard earned savings). Even four-year-olds have a tantrum if a parent violates their sense of fairness by awarding an undeserved privilege to a sibling." (p. 120)

\section{Expression of Emotions}

What about Darwin? His gentle elaborations on rage in The Expression of the Emotions in Man and Animals, [9] follow Francis Huxley's [10]arguments that the origin of species could easily have been named the origin of habit. To fly into a sudden rage attack can become an emotional habit. Darwin lists 39 passages on rage. For a taster: "We will now turn to the characteristic symptom of rage. Under this powerful emotion the action of the heart is much accelerated, or it may be much disturbed. The face reddens, or it becomes purple from the impeded return of the blood, or may turn deadly pale. The respiration is labored, the chest heaves, and 
the dilated nostril quivers. The whole body often trembles. The voice is affected. The teeth are clenched or ground together, and the muscular system is commonly stimulated to violent, almost frantic action. ...All this bodily signs of rage are probably in large part, and some appear to be wholly, due to the direct action of the excited sensorium. But animals of all kinds, and their progenitors before them, when attacked or threatened by an enemy, have exerted their utmost powers in fighting and in defending themselves. Unless an animal does thus act, or has the intention, or at least the desire, to attack its enemy, it cannot properly be said to be enraged. An inherited habit of muscular exertion will thus have been gained in association with rage; "(Darwin, 2009, p. 77-8).

He further observes the uttering of terrible yells by Gorillas, whose scalp is moved backward and forward in frenzy, the roaring of lions, a dog's growl and snarl - all intended to strike terror into the enemy. We humans often throw our arms wildly about, as if to make us larger in the threatening behavior signs, and yell too. Jaak Panksepp [11]in his investigation of Affective Neuroscience - The Foundations of Human and Animal Emotions, sees the primary emotional systems of rage and fear as intermingled. According to him, anger is generated by stimuli in the social environment, whereas rage is triggered by neural circuits. As he points out, '.... human baby typically becomes enraged if its freedom of action is restricted simply by holding its arms to its sides' (p. 189). Our brains, formed by experience and evolutionary processes, have been conditioned to search for the motives of strong feelings outside ourselves. Besides the reflex that tells us to play dead, rage is our next best survival strategy, allowing us, when preyed upon, to escape our enemy's imminent deadly bite. The sudden, violent rages which are the subject of this chapter are powerful thrusts of energy that can enable us to escape from deadly threats to our lives. This characteristic is a basis for the future development of our emotional lives. As mature adults we can express our primitive emotional impulses in words and through language, thanks to years of socio-cognitive learning.

Within the context of social anthropology, I can take into account the interwoven cultural and contextual history of European living arrangements, by now mostly taking place in cites (up to $80 \%$ of the population). As we have seen with the recent 'days of rage' in England for example, the arenas of alienation - youth poverty, racial strife, violence, unemployment - focused on in the local settings of neighbourhoods, sports clubs, bars, social clubs, discos and streetlife - all play a decisive role in the fabric which creates the politics of experience. Jerram [12]) organises his social anatomy of city living around five broad themes: politics, culture, woman's lives, sexual identities, and the impact of planning. The use of urban public spaces in cultural events, urban unrest, and social upheavals is a political issue in itself. In terms of expressing rage and enragement in public spheres, "ferocious disputes over space turned street politics into high politics." (Rabinbach [13]) When members of high politics speak of a younger generation of immigrants as a 'mob', then those people, who are in the process of integration and acceptance of life's condition, trying democratically get their voices going and heard, are hunted down by those in power using their police against those in powerless positions, using their anarchic energy often ending in running dead-end battles. (14) The Week, 13. August, 2011). This resembles the prime maxim of the Ik, the mountain people of Uganda, researched between 1964-1967 by Colin Turnbull, that “... each man should do what he wants to do, that he should do anything else only if he is forced to." [15], p. 152) Yet, contrary to the politicians' tactics of 'divide and rule',

the youth movements, in expressing rage against social-political arrangements servicing mostly the powerful and rich of any society, are moving in a collective dream action.

\section{The Research}

Many individuals experience sudden rage as a personal, and often inherited, emotion. The destructive power of these rages, bursting unannounced into our daily lives, is well-known and yet often considered by society as taboo. Many children of raging parents, and many partners of raging men and women, suffer the psychological and physical injuries caused by these uncontrollable bursts of emotion. We are witness to outbursts of rage within the family, in relationships, on the road, at work, and in schools and institutions. We stand helpless before the open secret of a veritable plague to society. In the interests of gaining some clarity on this a team of researchers surveyed 481 pedestrians in eastern Switzerland between March and June of 2006 about their experience with outbursts of rage. In addition, another 94 people serving as a control group were surveyed by phone in August 2006 in three cities: Bern, Zurich and Basel [16] In this discussion I will try to answer some diverse open questions concerning the phenomenon of sudden rages. Our sociological research addresses concrete, real-life problems. The investigation into rages presented here applies to all those affected by them, be they victims or perpetrators. Using this questionnaire, oriented towards qualitative social research, we made the following discoveries, amongst others:

$24 \%$ of the population of the German areas of Switzerland are 'ragers'.

$22 \%$ of the population are, or feel themselves to be, victims of sudden rages.

$36 \%$ of the people questioned come, as affected person into contact with rage in a domestic situation.

$68 \%$ of the people who admitted to outbursts of rage experienced these mostly in a family setting.

These data sources gathered from different regions in different ways - on the street and on the phone - allowed us to make a critical comparison of the results. This empirical, socio-psychological research conducted for my book RAGE-Managing an Explosive Emotion (16) Itten, 2011), used quantitative and qualitative methods. Through the medium of qualitative analysis, and with the help of 'grounded theory', I have tried to quantify various sections of answers in our survey in a consistent way, using 'sets.' 
(Strauss, 17) "Grounded theory consciously permits the building of concepts (codes and constructs) during the data survey and seeks to make them transparent" [19], p. 104). The goal of analysing text-based answers in this qualitative way is to make both their manifest and latent sense-structure comprehensible and statistically useful. This is done by abstracting them into sets which summarise their content. The results of our research can then be either backed up or disproved at any time by a wider study using the same system of categories and sets.

The demographic breakdown of the 575 participants in the survey (259 men, 316 women) gives a good cross-section of the population. $36 \%$ of the 575 participants had come into contact with sudden rages in their family. In total, a good fifth of the sample $-22 \%$ - identified themselves as given to outbursts of rage. Most people who identify themselves as ragers are between the ages of 20 and 29, and 40-49. In terms of gender difference, of these self-identified 'perpetrators', it was only in the 30-39 and 40-49 age groups that the women outnumbered the men. Otherwise the men were always slightly in the majority. $66 \%$ of ragers noticed their tendency in childhood and puberty. Men experience rage more often during conflicts and emotional arguments in relationships. People who can learn and practice regulation of their emotions by the end of puberty will probably no longer experience sudden rages. In the world of psychology, and psychopathology, this sudden and violent expression of rage is sometimes viewed as an affective personality disorder, in only one of the eight criteria of Borderline Personality Disorder, and as a marker of an unbalanced, choleric character style.

\section{Data Analysis}

Sudden rage didn't count as a mental disorder in either of the two trend-setting international systems of classification, the ICD-10 and the DSM until this year. The debate in a group of experts on the newly published DSM-5, (May 2013), goes so far as to diagnose sudden rage now as a Disruptive Mood Dysregulation Disorder (296.99/F34.8) or Intermittent Explosive Disorder (312.34/F63.81). Here, verbal rages and physical aggression towards people or property are seen as diagnostic criteria, if this happens up to three times a week. Interestingly, the first diagnosis is placed in the group of depressive disorders. Lots of people who do suffer from sudden rage do implode after their explosion of emotions into an intermitted depressive episode, expressing their sadness that this has happened again. This is the momentum to catch them in for psychotherapy, as this is the so called "honeymoon" phase in the triangle of domestic violence. If not motivated in this "weak" stance, the build-up of repressed or bottled up emotions will climb up one side only to peak, once again, into a sudden rage attack.

In a study addressing the question 'Can we prevent road rage?' researchers from the Centre for Addiction and Mental Health at the University of Toronto investigated how the growing concern over personal safety on the roads could be addressed [18] Asbridge et al, 2006). They reviewed 73 scientific works which took on the issues of aggressive driving and behaviour on the road, brought together in the concept of road rage. Their operative definition of road rage is: a driver or passenger tries to kill, injure or intimidate another driver or passenger, or to damage their vehicle in a collision. A study from the UK revealed that of 60 road traffic accidents involving road rage, $20 \%$ ended with a fatality and $48 \%$ with a serious injury. Most of the really dangerous perpetrators of road rage are young men, often drunk, and with psychological problems, who drive in a reckless and aggressive manner. In a study of 2,942 drivers in Ontario, almost half had been shouted at or had rude gestures made at them by other drivers. However, only $7.2 \%$ of them had been seriously verbally threatened. These authors, [19] Smart, R. G. et. al, 2003) recommend that drivers failing their tests for driving aggressively should be identified as potential road-ragers by using the test for Intermittent Explosive Disorder. What this overview of the research already done on road rage shows is that society is getting more violent, and road rage is just one visible symptom of this general trend. Congested roads - socio economic context - are also seen as triggers. Motorway tailbacks, according to an investigation in the US, increased by over $41 \%$ between 1990 and 2002 and might by now be doubled up in Europe as well as the US. Airplane passenger rage has also become a recognised and studied phenomenon. As with road rage, the people most often responsible for this are heavy-drinking young men.

\section{Social Anthropology}

It is generally agreed among social anthropologists that all human beings have, without exception, a language, techniques, arts, positive knowledge, religious imaginations, a social, and a political organisation of their everyday living situation. Careful studies in Australia, Melanesia, South America and Africa have shown that two to four hours of activity have been ample to secure survival for all the families in a tribe. The rest of the day could be spent in storytelling and giving the imagination and myth a field day.

The demand for more consumption in our modern fragmenting society is psychologically created through advertising, and we serve an ever growing market. The demoralising result is that now more than ever people worldwide are drawn to big cities. That means being caught in an artificial life habitat, estranging us all more and more from natural human nature.

Social anthropology gives us the opportunity to study the human spirit in different settings and collective endeavours, managing through difficulties which their geographic givens and historical fate has given those means to survive. As a psychologist, the details are vital, and we better pay close attention. What are the collective moral and ethical motivations which make a tribe successful even though its individual member might not have a clue, except to know the larger story presented in their myths, giving meaning for day 
to day living? We aim for a totality of seeing what is taking place at any one time in a society under objective participant observation. Were the tribes of old not much more successful than our society's leaders to reach an enduring balance between natural environment and human demands? We only have to reflect on the days of rage in Tunisia, Egypt, Libya, Brazil and London, since 2011. One main issue is, how can we all fulfil our biological and soul desires in our social settings? Reports of health and wealth show that this is less and less possible.

Again I remember the Ik, only held together in their tribal society through violence. A variety of ideological explosions: Capitalism, Marxism, Nazism, Fascism and Totalitarianism are brutal destroyers of content and context of community living. Societies have habits, rituals and institutional dogmas of faith, and lots of people see this, following their leaders with vested interest, whether God given or natural. The responsibility is no longer to and within a community and society; it is now returned to the individual where a minimal mutual dependence still holds thinly as a membrane of civilisation. To endure and to change, that is the question. Stability is what is longed for, be those in the habits and myths, belief systems and strategy solutions. The management of the unexpected makes great and good use of the potential difference in the resources of individuals in our socially hierarchically organised society. "Culture contains the totality of relationships which human beings within a given civilisation cultivate; more precise, this society rests on the relationships, which these human beings have with one another." [20]Lévi-Strauss, 2011, p. 91)

Implicit in this system of determinants are subtle contortions making it very difficult, if not impossible for most of us, to actually have a clue that our system of reference is only one among many possible human cultures. By facing our lived reality, as a drama of self and others as well as powers larger than us, we are no longer plastering it over with words and concepts.

\section{Psychotherapeutic Challenge}

As an attendant to the cooled down souls or psyche ${ }^{\mathrm{vi}}$, aiming to warm them up again with my healing art, I am practising in a psychoanalytic and integrative body psychotherapy tradition. Our feelings of self-worth and self-confidence are fed by the trustworthiness of our emotions. We are already always embedded in a social, economic, cultural life conditioning context where our present content of meaning, aim and purpose is filled in. The less clear our own social identity is, the more necessary and desperate our inner search for a foothold. If our inner and outer footing in life is upset, by adversities such as emotional, physical or sexual abuse, we become insecure. Children will then develop feelings of anger, resentment, irritation or rage, and use these to protect themselves from disappointment. This can, but does not have to, lead to emotional poisoning. What can we do?

With the help of psychotherapy, we can feel the experience that hurt us once again, and integrate it into our adult selves. This can be managed successfully in therapy. In the presence of a therapist, one need no longer fear one's own boiling emotions. If I have the courage to take another look at my emotional knots, untangle them, and let the genie of my stored-up pain 'out of the bottle', I come to the experience that lies at its source. I can re-experience that earlier situation, but as an adult, in the healing presence of another adult. The regulation of rage can be done in a variety of ways, depending on the cultivation of emotions and feelings within the family of origin. Jean Briggs [21], an anthropologist following the Utku Eskmios in the area near Hudson Bay, noted that every display of anger in children over two years old was followed by parents and relatives becoming silent another proof that expression of emotions depends on social conditioning and social respectability. Psychoanalyst Michael Eigen [22] mentions that one of the worst aspects of rage is the affinity between this powerful emotion and the claim of self-righteousness. Rage is an attempt to fill the inner void, he thinks, which is doomed to failure, and which masks an inability to truly recognise one's own emotional life and show one's feelings. Paradoxically, seven out of 100 people who suffer from sudden rage don't want to be cured of it, as our survey results show. The new experience of expressing our own rage passionately and directly, without it being sudden and destructive, is proof of our mental and social maturity.

My operating principles of therapy are as follows: Foremost is the theory of the basic fault. The fault in the base of our being is that our human and our animal natures lie in close proximity, and flow into each other (Balint, [23]This fact is seen by most moral and ethical religious scholars as a human flaw. Kierkegaard, Nietzsche, and other thinkers, who were tormented by pain, give us the insight that there is no escaping this existential pain. All the religious and esoteric lies and illusions in the world cannot convince us that we are something other than highly domesticated animals. This truth will set you free. Free to live according to the true nature that slumbers within us - and that means being able to express our feelings of rage as well as joy. A moment of sudden rage is an attempt to break free of the complications of nature and culture. It is an attempt to escape tightening emotional knots of our animalistic nature, from those of the reason-loving human.

'There is no healing without sympathy' wrote Ferenczi [24]in his diary, just as love is the beginning of all the healing arts. This principle helps me to make use of the distinction between the true and the real world. The embodied 'real' personal and social world we live in is, and remains, finite. The 'true' dreamed, prophetic, imagined world is infinite. Modern psychotherapy researchers agree that the way in which I as a psychotherapist characterise my relationship to my patients constitutes $30 \%$ of the therapy's effectiveness. The 'patient factor,' the way in which he or she lives, their job, social life and love life, their housing situation, the patterns they have inherited from past generations, accounts for $40 \%$ of the effectiveness. The 
method of psychotherapy that is actually used, in my case Analytic and Integrative Body Psychotherapy, is only charged with $15 \%$ of the effectiveness of the process and healing - the same amount as the placebo effect (Lambert and Bergin [25]; Tschuschke and Kächele [26].

\section{Evidence Based Strategies to Manage Explosive Emotions}

As psychotherapeutic practitioners we have a clear role to play in helping those who suffer from rage to devise positive strategies to manage their explosive emotions in their social situation so that they may develop alternative ways of being. Treating rage suffers may enable them to build a deeper sense of self-esteem and self-confidence, in their social selves, so that they learn strategies to defuse anger and cope with situations which previously might have triggered a bout of rage. Making sudden rage an issue to focus more closely on domestic violence, the psychotherapists' contribution is then to help alleviate this painful violent treatment of each other in a family. In this setting perpetrators and victims are closely interlinked. It takes resolute clarity in enforcing a stop of this domestic violence. Where words fail often fists speak compensating the lack of power.

What is the politics of helplessness doing these days? Modern psychotherapy research refers to this as the process of cognitive restructuring. In Switzerland, practitioners of Jungian psychotherapy spent eight years conducting empirical tests. Mattanza et al [27], present their results by stating that it often requires long-term psychotherapy 90-120 consultations - to restructure a person's life in a lasting way. Freeing somebody merely from symptoms and helping to alleviate interpersonal difficulties, a short term psychotherapy might usually suffice. The success of a course of psychotherapy, however, depends on many kinds of factors such as: health, level of social functioning, the length of time symptoms have been in place before the start of psychotherapy, age, sex, class, education, religion, work situation, family history, etc., are all of enormous importance. Furthermore, the Swiss Charter for Psychotherapy (www.psychotherapiecharta.ch) has undertaken a major naturalistic social scientific study, from 2007-2012. The Naturalistic Psychotherapy Study on Outpatient Treatment in Switzerland (The PAP-S Study - Psychotherapiestudie Ambulante Psychotherapie - Schweiz) was designed as a process-outcome study. In addition to a comprehensive battery of tests (tests and objective diagnoses and ratings by experts), the therapeutic bond is evaluated every five sessions (by client report / Helping Alliance Questionnaire). This study by 86 therapists, from nine different psychotherapeutic institutes, recruited a total of 362 patients (238 women, 124 men) aged between 17 and 72. Preliminary results have been published by Professor Dr. Volker Tschuschke et al., Department for Medical Psychology at the University of Cologne and the Department for Applied Psychology at the School for Applied Sciences in Zurich. (Tschuschke [28, 29].
The role of therapists' treatment adherence, their professional experience, therapeutic alliance and clients' severity of psychological problems, are shown to be interdependent in their producing a positive outcome

This can mean, for us psychotherapists, violent rage and sudden rage are still slightly taboo subjects. Nevertheless since this emotion is part and parcel of our animal-human-nature there is a necessity to meet this strong feeling within us while in a training therapy or analysis. As seniors in the field we can encourage our apprentice to own up to their range of emotions, from slight irritation, qualms, annoyance, then up the emotional curve to anger, fury and rage. We thus show them by doing and being authentic in our emotions enabling them to come along nicely as junior fellows unafraid of their being human. Our ancestor Sigmund Freud has been credited with the remark that analysis and therapy helps us to be no longer ashamed of whom we are to pluck up the courage to cultivate the vitality we once had as children and live it from the matured core of our wisdom from the heart.

\section{References}

[1] Roberts, R., Becirevic, E. \& Paul, S. (2011) Truth and Denial: Psychological Perspectives on Reconciliation in Bosnia. In: Elford, R. J. (Ed.) Just Reconciliation. Bern: Peter Lang.

[2] Samara, T. (2005) SREBRENICA - 11/07/95. Sarajevo: Agencija Grazia Neri.

[3] Peress, G. (1994) Farewell to Bosnia. Zürich: Scalo.

[4] Gowers, E. (2012) Design on Nature. London: TLS, August $17 \& 242012$ No5707/8.

[5] Borger, S. (2012) Tollster Tag meines Lebens. St. Galler Tablatt, Montag, 6. August, p5.

[6] Reich, R. (2012) Beyond Outrage. New York: Vintage Books

[7] Day, E. (2008) 'If anyone else says: Cheer up, love 'London: The Observer. 15. June, 2008.

[8] Kagan, J. (2012) Psychology's Ghosts. New Haven: Yale University Press.

[9] Darwin, C (1872 / 2009) The Expression of the Emotions in Man and Animals. Oxford: Oxford University Press.

[10] Huxley, F. (1959) Charles Darwin - Life and Habit. American Scholar, 1959, Vol. 29, 30, No. 4, 1,

[11] Panksepp, J (1998) Affective Neuroscience - The Foundations of Human and Animal Emotions. Oxford: Oxford University Press.

[12] Jerram, L. (2011) Streetlife. Oxford: University Press.

[13] Rabinbach, A. (2012) Violence and the City. London: TLS, August 5, No 5653, 7-8.

[14] The Week (2011) The Rule of the Mob-How the police lost control of our cities. 13. August, Issue 830, p. 4.

[15] Turnbull, C. (1974) The Mountain People. London: Picador. 
[16] Itten, T. (2011) Rage - Managing an Explosive Emotion. Faringdon: Libri Publishing.

[17] Strauss, A. \& Corbin, J. (1990) Basics of Qualitative Research: Grounded Theory Procedures and Techniques, 2. Edition. Thousand Oaks, CA: Sage Publication (17) Mayring, P (2002) Qualitative Sozialforschung. Weinheim, Belz.

[18] Mark Asbridge, Reginald G. Smart, Robert E. Mann. Can We Prevent Road Rage? April Trauma Violence Abuse. 2006 Apr; 7 (2): 109-21.

[19] Smart, R. G; Mann, R. E. \& Stoduto, G. (2003) The prevalence of road rage: estimates from Ontario. In: Canadian journal of public health. Revue canadienne de santé publique. 94 (4): 247-50.

[20] Lévi-Strauss, C. (2011) L'Athropologie Face Aux Problèmes Du Monde Moderne. Paris Seuil.

[21] Briggs, J. L. (1970) Never in Anger. Portrait of an Eskimo Family. Harvard: Harvard University Press.

[22] Eigen, M. (2002) Rage. Middletown, CT: Wesleyan University Press

[23] Balint, M. (1968) The Basic Fault - Therapeutic Aspects of Regression. London: Tavistock

[24] Ferenczi, S. (1988) Ohne Sympathie keine Heilung. Frankfurt: Fischer (Casper, M. J. (1998) The Making of the Unborn Patient: A Social Anatomy of Fetal Surgery. New Brunswick, NJ: Rutgers University Press.

i Rage The word 'rage' dates from around $1300 \mathrm{AD}$, and comes from the Old French raige. It also has roots in the Latin rabia: madness, rage or fury. 'Rabies' or hydrophobia also comes from this root, and the physical symptoms of this frothing at the mouth, lashing out in fury - are like an extreme outburst of the kind of rage. Anger The word 'anger' originates in the 12th Century AD, from the Old Norse angra, 'to grieve or vex'. It also has a root in the Greek ankhein, 'to squeeze', and the Latin angere, 'to throttle or torment'. We talk about being 'choked up' with anger: an angry person is strangled by his emotion, whereas the person who succumbs to a sudden rage has a valve to release the pressure.

iii Took place in Ascona, Switzerland June 3-4, 2011

iv United Nations, Prosecution Opening Statement, ICTY vs. S. Galic, 2003.

v Roberts, R., Becirevic, E. \& Paul, S. (2011, p. 146)

vi Psyche: mind, soul, disposition, state of mind. In ancient Greek, psyche meant 'the breath of life', from the Greek verb psychein: 'to breathe, to live'. Therapy: a healing treatment. Greek: therapeia, 'serving; service', from therápon, 'servant, companion'. These meanings constantly lead and inspire me as a psychotherapist.
[25] Lambert, M. J. \& Bergin, A. E. (1994) The effectiveness of psychotherapy. In: Bergin, A. E. \& Garfield, S. L. (Eds) Handbook of Psychotherapy and Behaviour Change. New York: Wiley pp. 143-189.

[26] Tschuscke, V. Kächele H (1998) Was Leistet Psychotherapie? In: Fäh, M. \& Fischer, G. (Eds.) Sinn und Unsinn der Psychotherapieforschung. Giessen: Psychosozial Verlag pp. 137-162.

[27] Mattanza G Meier I Schlegel M (2006) Seele und Forschung Ein Brückenschlag in der Psychotherapie. Basel: Karger.

[28] Tschuschke, V., Crameri, A., Koemeda, M., Schulthess, P., Von Wyl, A., Weber, R. (2010) Fundamental Reflections on Psychotherapy. Research and Initial Results of the Naturalistic Psychotherapy Study on Outpatient Treatment in Switzerland (PAP-S). International Journal for Psychotherapy: Journal of the European Association for Psychotherapy (EAP) 14 (3) Nov 2010, 23 -35.

[29] Tschuschke, V., Crameri, A., Koehler, M., Berglar, J., Muth, K., Staczan, P., von Wyl, A., Schulthess, P. \& Koemeda-Lutz, M. (2015). The role of therapists' treatment adherence, professional experience, therapeutic alliance, and clients' severity of psychological problems: Prediction of treatment outcome in eight different psychotherapy approaches. Preliminary results of a naturalistic study. Psychotherapy Research. Volume 25, 2015 - Issue 4, pp. 420-434. 